\title{
PROTOTYPE SMARTHOME DENGAN CATATAN WAKTU SAAT MEMBUKA PINTU DAN KONTROL NYALA LAMPU BERBASIS INTERNET OF THINGS
}

\author{
Farid Baskoro S.T., M.T¹, Arif Widodo S.T., M.Sc ${ }^{2}$, Rifqi Firmansyah S.T²., M.T, Aristyawan Putra \\ Nurdiansyah S.T ${ }^{4}$. \\ ${ }^{1,2,3,4} \mathrm{~S} 1$ Teknik Elektro, Fakultas Teknik, Universitas Negeri Surabaya \\ ${ }^{1}$ faridbaskoro@unesa.ac.id \\ 2 arifwidodo@unesa.ac.id \\ 3 rifqifirmansyah@unesa.ac.id \\ 4 aristyawanputra17@gmail.com
}

\begin{abstract}
Abstak - Internet of things (IOT) merupakan hal yang sudah tidak bisa dihindari. Semakin bertambahnya tahun, kebutuhan menggunakan IOT semakin meningkat. IOT mampu diaplikasikan dalam banyak hal termasuk dalam pelayanan rumah atau biasa disebut dengan smarthome. Oleh karena itu, penelitian kali ini akan memanfaatkan IOT sebagai pelayanan keamanan rumah. Tidak hanya diterapkan sebagai pelayanan keamanan rumah, tetapi penelitian kali ini juga menerapkan IOT kedalam sistem penerangan rumah. Hasil dari penelitian menunjukan bahwa sistem keamanan rumah berfungsi dengan baik dengan pengiriman data waktu serta identitas diri saat memasuki rumah, dan nyala atau mati lampu rumah mampu dikontrol menggunakan internet.
\end{abstract}

Kata Kunci: IOT, smarthome, RFID.

Abstract - Internet of things (IoT) is an irrevocable thing. As the year increases, the need to use IoT is increasing. IoT can be applied in many ways, including in home services or commonly called smarthome. Therefore, this research will use IoT as a home security service. Not only implementing a home security system, but also researching IoT in a home lighting system. The results of the study show how the home security system uses by sending data on time and identity when transferring houses, and the lights on or off home lights can be controlled using the internet.

Keywords: IOT, smarthome, RFID.

\section{PENDAHULUAN}

Internet of things (IOT) merupakan hal yang tidak bisa dihindari pada tahun belakangan ini. Semakin bertambahnya tahun, kebutuhan menggunakan IOT semakin meningkat dan setiap jengkal kehidupan sehari-hari bergantung dengan pengiriman data (Puspitaningayu, P, 2018). Dengan bergantungnya kebutuhan sehari-hari pada pengiriman data, kini IOT mampu diterapkan dalam hal pelayanan rumah dan mendukung semua perangkat dalam rumah dapat dihubungkan dalam berbagai aplikasi (Durani. Homera, dkk, 2018). Dengan menerapkan IOT dalam pelayanan rumah, maka mampu memberikan perubahan signifikan dalam mempermudah kehidupan manusia (Singh. Himanshu, dkk, 2018). Pelayanan rumah yang sangat penting yaitu keamanan rumah itu sendiri. Oleh karena itu, pada penelitian kali ini, IOT akan dimanfaatkan untuk sistem keamanan rumah. Sistem keamanan rumah menggunakan RFID sebagai acuan kunci untuk membuka pintu rumah. Kemudian saat RFID membaca kartu, disaat itu juga sistem akan mengirimkan data waktu saat
RFID melakukan pembacaan kartu menggunakan internet menuju ke smartphone. Pemilik rumah akan mengetahui kapan saja RFID bekerja membaca kartu ID yang digunakan untuk memberi akses membuka pintu.

Selain sistem keamanan rumah, hal lain yang perlu diperhatikan yaitu sistem penerangan rumah. Dapat diperdiksi bahwa semakin bertambah tahun maka sistem penerangan cerdas mampu menggantikan sistem penerangan yang biasa saja (Zhiguo. Meng, dkk, 2017). Hal ini menunjukan batapa perlunya kontrol penerangan rumah menggunakan internet.

\section{KAJIAN PUSTAKA}

Arduino promini merupakan board mikrokontroller yang memiliki dimensi kecil, memiliki berat sekitar 7 gram dengan dimensi $4,5 \times 1,8 \mathrm{~cm}$. Arduino promini dapat dihidupkan dengan sumber tegangan dari koneksi USB Mini-B, atau melalui sumber tegangan dari tegangan eksternal antara 3,3 5 volt yang dihubungkan melalui pin VIN, atau melalui sumber tegangan eksternal dengan tegangan 5 volt melalui pin 5 volt. Arduino promini menggunakan Atemga 328p dan 
dilengkapi dengan 14 pin digital input dan output serta 6 pin analog input. Pinout yang lebih detail dapat dilihat pada Gambar 1.

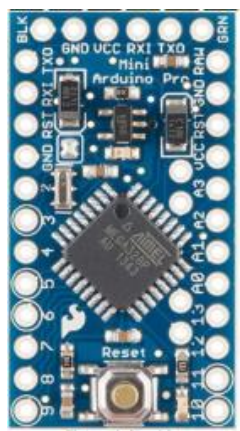

Gambar 1. Arduino Promini Board

Wemos D1 mini merupakan mikrokontroller yang sudah dilengkapi dengan esp8266 sehingga mampu langsung dikoneksikan dengan wi-fi. Wemos D1 mini memiliki 11 digital input/output pin, dan 1 analog input pin.

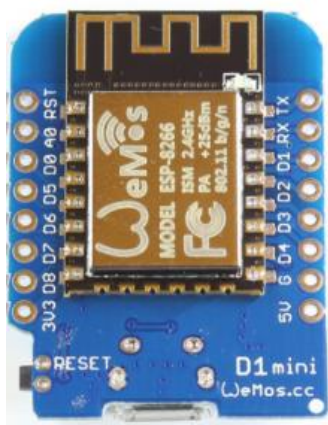

Gambar 2. Wemos D1 Mini

Radio Frequency Identification (RFID) adalah sebuah teknologi yang menggunakan komunikasi via gelombang elektromagnetik untuk merubah data antara terminal dengan suatu objek. Dalam suatu sistem RFID sederhana, suatu objek dilengkapi dengan microchip yang ditanamkan di dalamnya dan berisi sebuah kode tertentu. Bentuk RFID dapat dilihat pada Gambar 3.

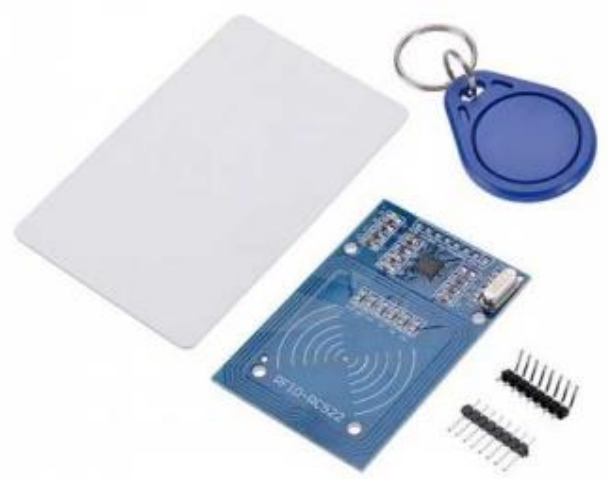

Gambar 3. RFID Modul
Modul RTC DS1307 merupakan modul yang bisa mengolah waktu tanpa mengganggu program utama dari mikrokontroller. RTC digunakan untuk mengetahui waktu saat RFID digunakan untuk mengakses keamanan rumah. Modul RTC dapat dilihat pada Gambar 4.

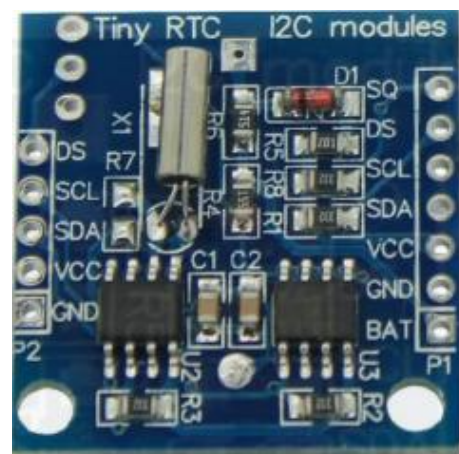

Gambar 4. RTC modul

Seleoind merupakan actuator yang bergerak maju mundur. Berbeda dengan motor pada umumnya yang bergerak memutar. Dengan pergerakannya yang manju mundur, dapat dimanfaatkan sebagai keamanan rumah. Bentuk solenoid dapat dilihat pada Gambar 5.

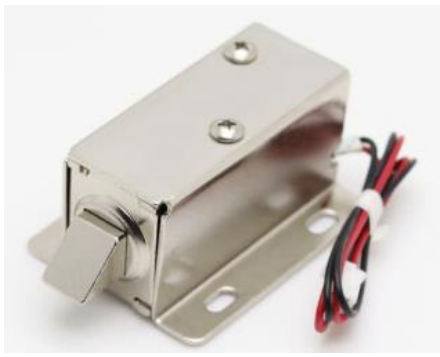

Gambar 5. Selenoid

Relay adalah suatu komponen yang bekerja berdasarkan elektromagnetik untuk menggerakan sejumlah kontaktor yang tersusun atau sebuah saklar yang dapat dikendalikan dari rangkaian elektronik lainnya dengan memanfaatkan arus listrik sebagai sumber energinya. Relay akan menyala karena efek induksi magnet yang dihasilkan kumparan ketika dialiri arus listrik. Berbeda dengan saklar, pergerakan nyala atau mati dilakukan manual tanpa perlu arus listrik. Gambar 6 menunjukan bentuk dari Relay 5v. 


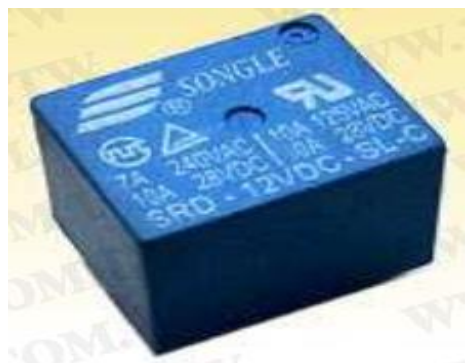

Gambar 6. Relay 5v

LED (Light Emitting Diode) adalah komponen elektronika yang mampu memancarkan cahaya ketika diberi arus listrik. LED biasanya berfungsi sebagai indikator tertentu pada suatu sistem. Bentuk fisik LED dapat dilihat pada Gambar 7.

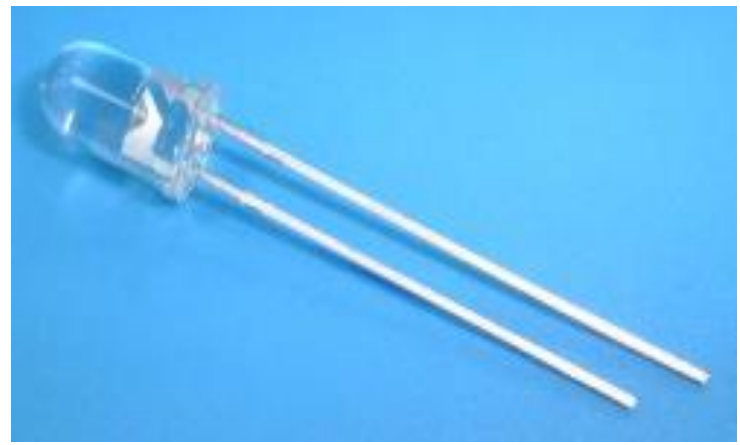

Gambar 7. LED 5mm

\section{METODE}

Tahap rancangan pada penelitian ini dimulai dari studi literatur, kemudian dilanjutkan dengan pembuatan desain sistem berupa perancangan software dan hardware.

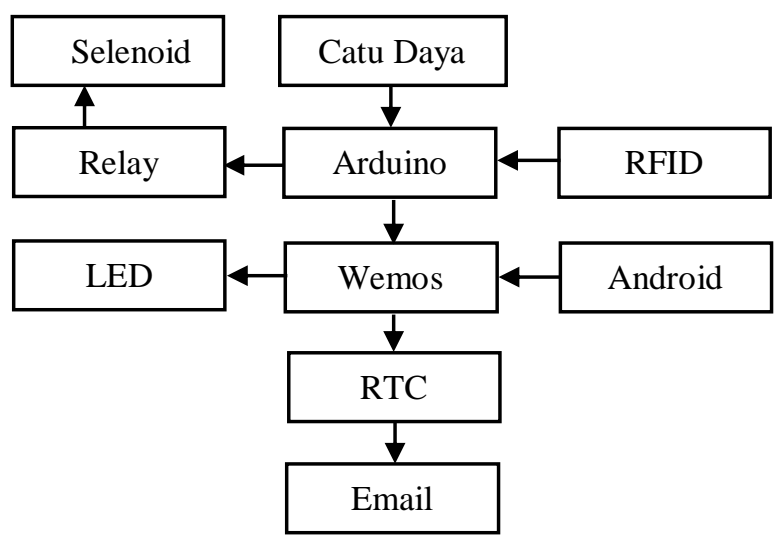

Gambar 8. Blok Diagram Sistem

Gambar 8 menunjukan blok diagram sistem prototype smarthome dengan catatan waktu saat membuka pintu dan kontrol nyala lampu berbasis internet of things. Untuk menyalakan alat, catu daya menggunakan tegangan sebesar $5 \mathrm{v}$ Ketika RFID mendeteksi adanya identitas kartu yang sesuai, maka Arduino akan menggerakkan relay agar solenoid bekerja sehingga pintu dapat terbuka. Disaat itu juga Arduino mengirimkan data identitas kartu dan memberi perintah kepada wemos untuk membaca waktu yang terdapat pada RTC kemudian mengirimkan data waktu serta identitas kartu tersebut menuju email.

Blok diagram android digunakan sebagai pengatur nyala ato mati LED yang terdapat pada rumah. Ketika android terkoneksi dengan internet, maka perintah untuk nyala atau mati akan dikirikan melalui internet dan diterima oleh wemos untuk merespon perintah dari android.

\section{HASIL DAN PEMBAHASAN}

Hasil dan pembahasan pada penelitian ini menyajikan data meliputi proses pemasangan RFID, solenoid, dan led pada prototype rumah, dan kinerja sistem.

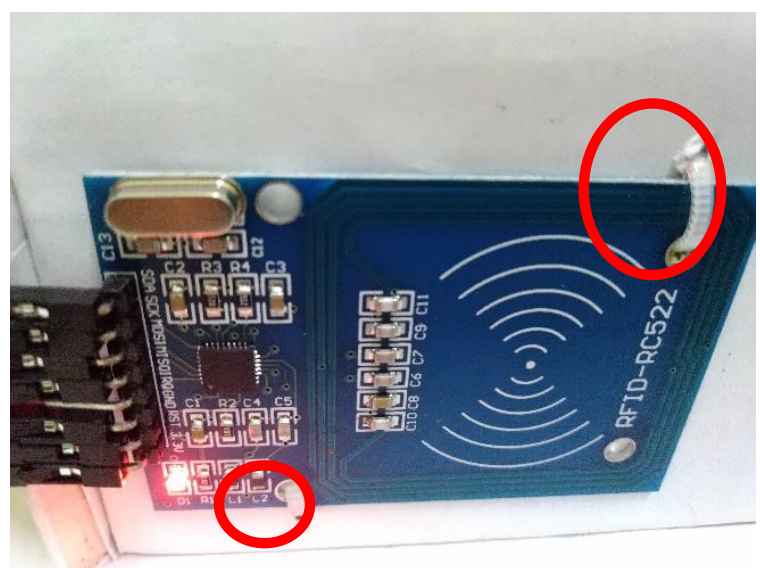

Gambar 9. Peletakan RFID

Peletakan RFID diletakkan di bagia luar rumah, hal ini bertujuan agar pemilik rumah mampu mengakses RFID dengan lebih mudah. Peletakan RFID ke tembok direkatkan dengan menggunakan bantuan dari kabel ties. Hal ini bertujuan agar RFID lebih kuat untuk merekat pada tembok rumah. Peletakan RFID dengan kabel ties dapat dilihat pada Gambar 9 dan hasil peletakan RFID pada tembok rumah dapat dilihat pada Gambar 10. 


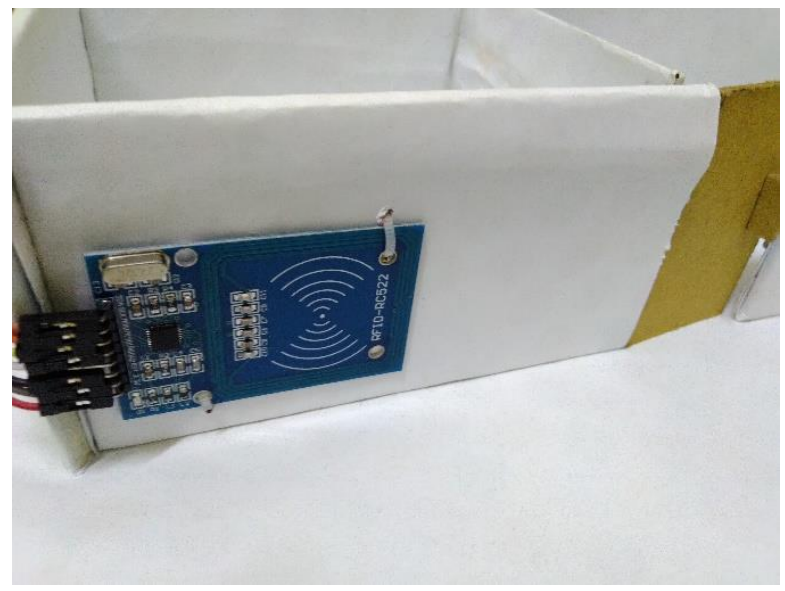

Gambar 10. Hasil Akhir Peletakan RFID

Peletakan solenoid diletakkan pada tembok terdekat dari pintu rumah. Hal ini dilakukan agar solenoid mampu menahan pintu agar tidak terbuka saat keadaan terkunci.

Perekatan solenoid pada tembok rumah dibantu dengan kabel ties. Foto perekatan solenoid pada tembok rumah dapat dilihat pada Gambar 11.

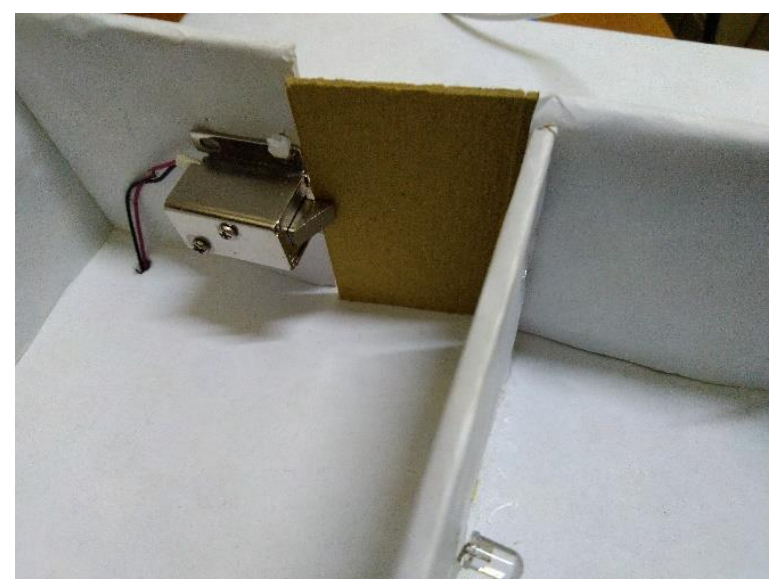

Gambar 11. Peletakan Selenoid

LED diletakkan pada bagian tembok, hal ini bertujuan agar mempermudah jalur pengkabelan agar tidak terlihat nampak dari luar. Pada penelitian ini, jumlah LED yang digunakan berjumlah 3 buah, yang mana akan diletakkan pada ruang tamu 1 buah dan diletakkan pada 2 kamar dengan masing-masing 1 buah LED pada setiap kamar. Foto peletakan LED pertama pada ruang tamu dapat dilihat pada Gambar 12, foto peletakan LED kedua pada kamar pertama dapat dilihat pada Gambar 13, foto peletakan LED ketiga pada kamar kedua dapat dilihat pada Gambar 14. Dan foto hasil akhir ketiga LED pada rumah dapat dilihat pada Gambar 15.

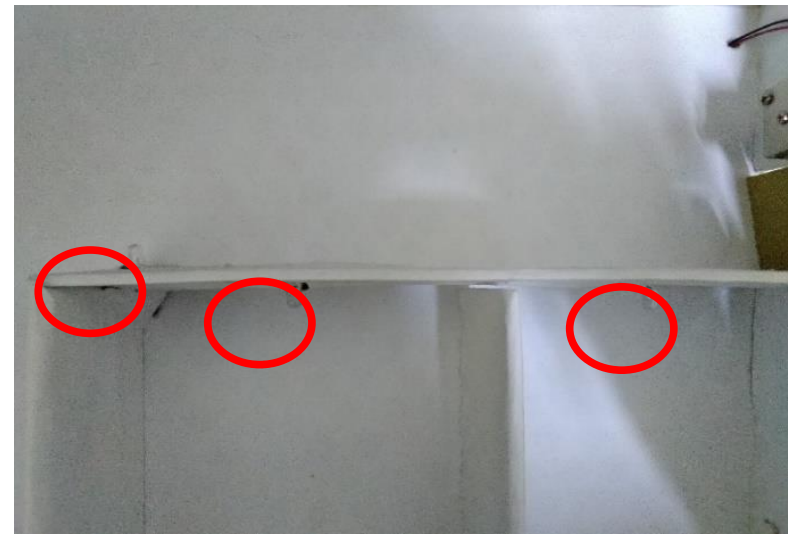

Gambar 15. Hasil Akhir Peletakan LED

RFID bekerja dengan cara membaca identitas kartu pada masing-masing kartu. Identitas kartu akan disimpan pada arduino terlebih dahulu. Hal ini bertujuan untuk mengenali siapa saja yang memasuki rumah dari identitas kartu yang digunakan. Kinerja RFID dapat dilihat pada Gambar 16.

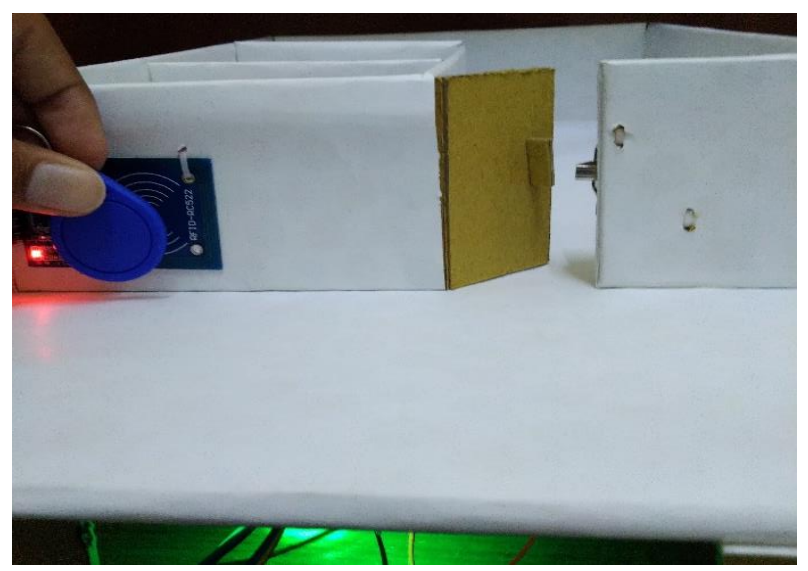

Gambar 16. Proses Pembacaan Identitas kartu dan Kinerja Selenoid

Pada Gambar 16 menunjukan bahwa kartu didekatkan pada RFID untuk mendeteksi identitas kartu yang akan memasuki rumah. Setelah kartu dibaca oleh RFID kemudian cocok dengan data identitas kartu yang telah disimpan di arduino, maka indikator lampu hijau dibawah prototype rumah akan menyala dan solenoid bekerja sehingga pintu tidak lagi terkunci.

Disaat yang bersamaan, Arduino mengirimkan data identitas kartu menuju ke wemos. Disaat wemos mendeteksi adanya kiriman data dari arduino, maka wemos langsung membaca data waktu dari RTC, kemudian mengirimakan data RTC bersama dengan identitas kartu yang mencoba memasuki ruangan melalui email. Hasil data yang dikirim menuju email dapat dilihat pada Gambar 17. 


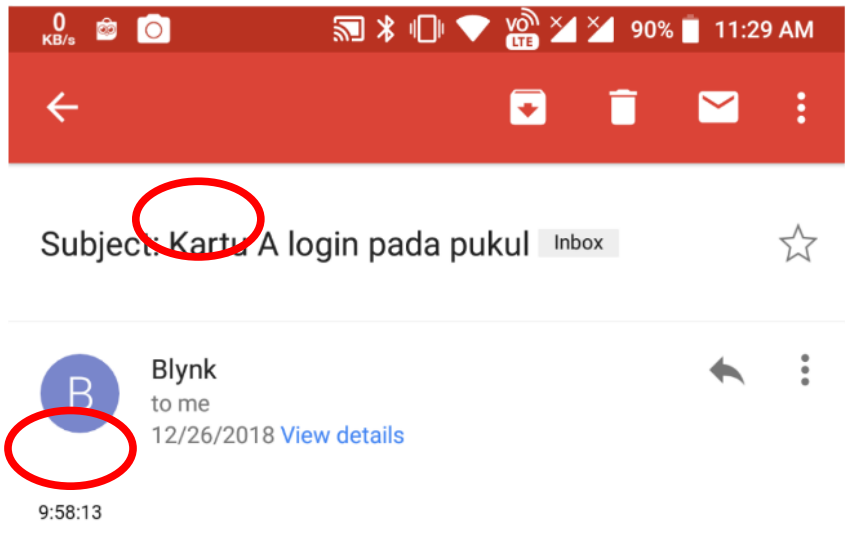

Gambar 17. Isi Email yang Diterima dari Wemos

Pada Gambar 17 dapat dilihat bahwa wemos mengirimkan identitas kartu berupa "Kartu A" dan mengirimkan waktu saat memasuki rumah pada pukul 9:58:13.

Pada saat kartu yang tidak terdaftar pada arduino mencoba untuk didekatkan pada RFID maka yang tejadi adalah RFID akan mengirimkan tanda bahwa kartu lain mencoba untuk memasuki rumah. Hasil data yang dikirim saat kartu lain mencoba untuk memasuki rumah dapat dilihat pada Gambar 18.

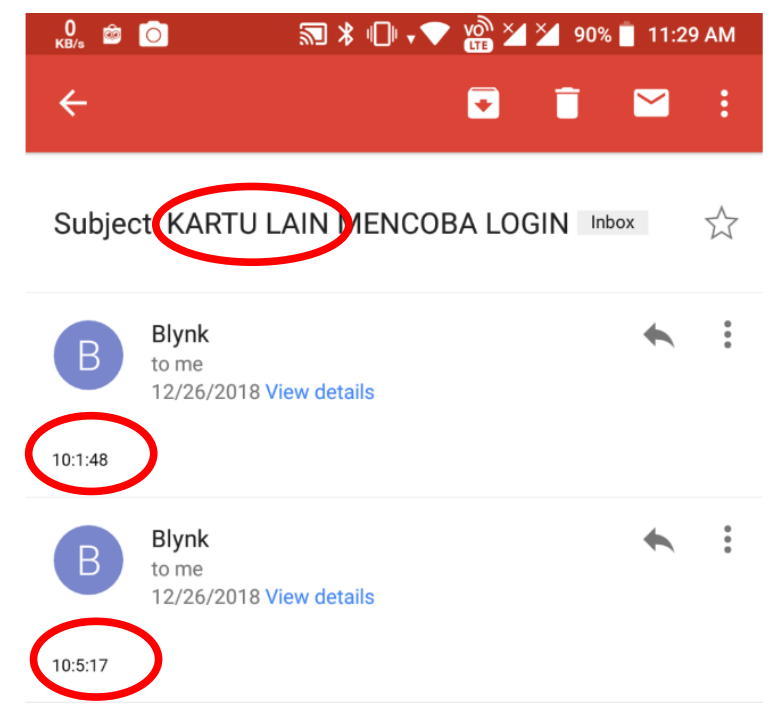

Gambar 18. Data dari Wemos saat Kartu Tidak Dikenali Sumber :(Data Primer, 2019)

Nyala atau mati lampu pada prototype rumah dikontrol menggunakan android dengan bantuan koneksi internet. Tampilan aplikasi android untuk mengontrol nyala dan mari lampu dapat dilihat pada Gambar 19

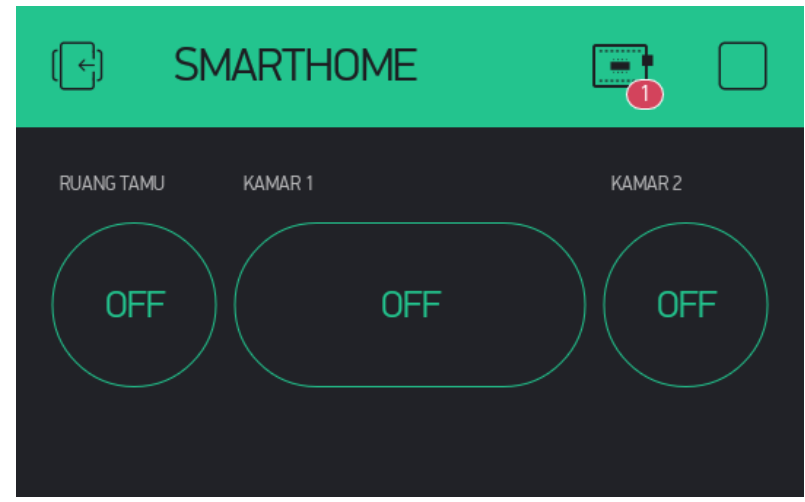

Gambar 19. Tampilan pada Android

Setelah perintah dilakukan dari android, maka wemos merespon data yang dikirim android melalui internet untuk menjalankan perintah. Hasil gambar nyala lampu dengan kontrol dari android melalu internet dapat dilihat pada Gambar 20.

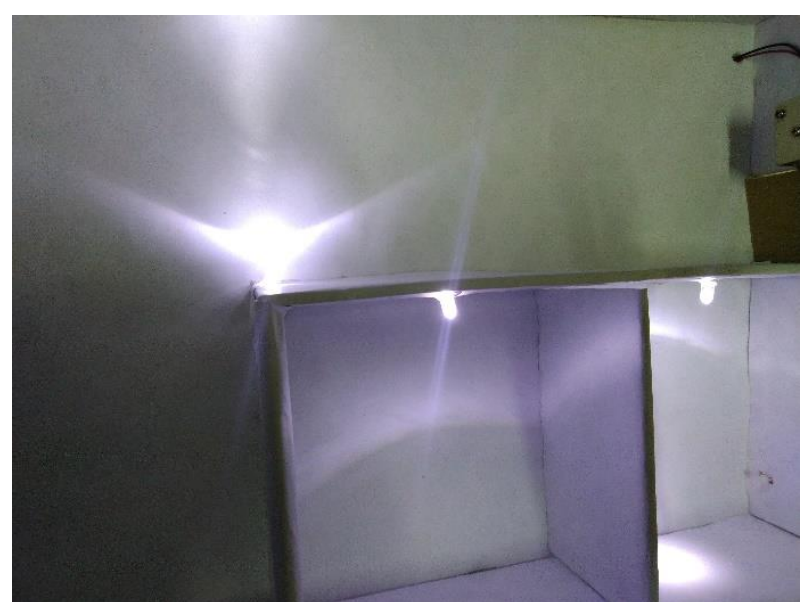

Gambar 20. Kondisi Nyala Lampu pada Prototype Rumah Sumber :(Data Primer, 2019)

\section{PENUTUP}

Dari penelitian yang telah dilakukan, dapat diambil kesimpulan pada prototype smarthome dengan catatan waktu saat membuka pintu dan kontrol nyala lampu berbasis internet of things telah berhasil dibuat dengan menggunakan RFID dan solenoid sebagai keamanan prototype rumah serta aplikasi android berhasil menyalakan lampu prototype rumah dengan menggunakan internet.

Pada penelitian yang telah dilakukan terdapat beberapa hal yang masih perlu disempurnakan. Hal pertama yaitu dalam penggunaan bahan dasar prototype. Bahan dasar prototype bisa menggunakan akrilik dengan diameter yang tebal agar prototype rumah menjadi lebih kokoh. Hal yang kedua yaitu 
penataan kabel, kabel lebih baik diberi selongsong supaya lebih terlihat rapi.

\section{DAFTAR PUSTAKA}

[1] Datashet Arduino Promini, "Programmed as Arduino Pro Mini w/ ATMega328,"

[2] Ecardio, "Modul RFID,". [Online] http://ecadio.com/jual-modul-rfid, tanggal akses : 4 Maret 2019.

[3] EscapeQuotes, "Wemos D1 Mini Pins and Diagram,". [Online] https://escapequotes.net/esp8266-wemos-d1-mini-pins-and-diagram/, tanggal akses : 4 Maret 2019.

[4] Everlight, "Technical Data Sheet 5 mm Round White LED (T-1 3/4),". Hal 1-10. July 2007.

[5] ,Homera Durani, Mitul Sheth, Madhuri Vaghasia, Shyam Kotech, "Smart Automated Home Application using IoT with Blynk App," IEEE Conferences., hal. 393-397. 2018.

[6] Lia Kamelia, Mufid Ridlo Effendi, Delingga Ferial Pratama, "Integrated Smart House Security System Using Sensors and RFID," IEEE Conferences., hal. 1-5. July 2018.

[7] Meng Zhiguo \& Wang Haiyan, "Design of LED Light Parameters Controlled Based on WiFi," IEEE Conferences., hal. 48-51. 2017.

[8] Puspitaningayu, P., Baskoro, F., \& Buditjahjanto, I. A. Komunikasi Data dan Komputer

[9] Songle Relay," Relay ISO9002" [Online] https:// www.hobbytronics.co.uk/datasheets/songle-12v-relay.pdf, tanggal akses : 4 Maret 2019.

[10] Tokopedia, "DS1307 RTC Real Time Clock,".[Online] https://www.tokopedia.com/warungarduino/ds1307-rtc-real-timeclock, tanggal akses : 4 Maret 2019.

[11] Tokopedia, "Solenoid door lock LY-03 DC12V kunci pintu otomatis $12 \mathrm{~V}$ RFID arduino," . [Online] https: //www . tokopedia.com/aisyah Arduino/solenoid-door-lock-ly- 03- dc12v- kunci- pintu- otomatis12v-rfid-arduino?m_id=5487012, tanggal akses : 4 Maret 2019. 